\section{Estudo \\ CoDebate}

em CAStão

Planejamento
Revista Estudo \& Debate, Lajeado, v. 27, n. 4, 2020. ISSN 1983-036X

DOI: http://dx.doi.org/10.22410/issn.1983-036X.v27i4a2020.2581

\title{
QUALIDADE DE VIDA NO TRABALHO: QUAL PERCEPÇÃO DOS FUNCIONÁRIOS DE APOIO E TÉCNICO DE UMA ESCOLA ESTADUAL EM RONDONÓPOLIS?
}

\author{
Amanda Paula Lima Borges ${ }^{1}$, Edir Vilmar Henig ${ }^{2}$
}

\begin{abstract}
Resumo: Uma das grandes preocupaçóes do mundo corporativo contemporâneo é a qualidade de vida dos trabalhadores no ambiente laboral. Esta preocupação tem se deslocado também para o setor público, em suas várias categorias de serviços. A educação é um segmento de serviços públicos que merece atenção, sendo objeto de estudo, não apenas os professores, mas também os técnicos e demais profissionais de apoio educacional. Sendo assim, esta investigação se debruça em analisar as percepçóes dos servidores que ocupam os cargos de apoio administrativo educacional e técnico administrativo educacional qualitativamente, sobre Qualidade de Vida no Trabalho e em identificar se há a existência de um programa de QVT na unidade escolar Edith Pereira Barbosa. A teoria de Walton (1973) é a base que norteia esta pesquisa, e o questionário foi elaborado diante das oito dimensóes apresentadas pelo autor. Os resultados apresentados foram em parte divididos entre as opinióes positivas e negativas a partir da percepçáo da teoria utilizada.
\end{abstract}

Palavras-chave: Qualidade de Vida. Setor público. Teoria de Walton (1973).

\section{QUALITY OF LIFE AT WORK: WHAT PERCEPTION OF THE SUPPORT AND TECHNICIAN EMPLOYEES OF A STATE SCHOOL IN RONDONÓPOLIS?}

\begin{abstract}
One of the major concerns of the contemporary corporate world is the quality of life of workers in the workplace. This concern has also shifted to the public sector, in its various categories of services. Education is a segment of public services that deserves attention, being the object of study, not only teachers, but also technicians and other educational support professionals. Therefore, this investigation focuses on analyzing the perceptions of the employees who occupy the positions of educational administrative and technical administrative support qualitatively on Quality of Life at Work and seek to identify whether there is a QVT program within the Edith school unit Pereira Barbosa. Walton's theory (1973), is the base, which guides this research, the questionnaire
\end{abstract}

1 Graduada em Administração pela UFMT.

2 Doutor em Território, Risco e Políticas Públicas pela Universidade de Coimbra. Mestre em Política Social e Graduado em Administração pela Universidade Federal de Mato Grosso. Graduado em Ciências Contábeis pela Universidade de Cuiabá. Professor no Curso de Administração na Universidade Federal de Mato Grosso, Campus de Rondonópolis. 
was elaborated considering the eight dimensions presented by the author. The results presented were partly divided between positive and negative opinions based on the perception of the theory used.

Keywords: Quality of Life. Public sector. Walton's Theory (1973).

\section{INTRODUÇÃO}

Atualmente, a Qualidade de Vida no Trabalho (QVT), tem se tornado cada vez mais um fator primordial nos ambientes organizacionais. Com o principal intuito de promover melhores condiçóes de trabalho aos funcionários, a QVT tem sido utilizada pelas organizaçóes, na busca por resultados mais eficientes, por parte dos colaboradores.

Ao adotarem programas de qualidade de vida as empresas podem obter retornos positivos, tais como: melhoria no comportamento dos funcionários, melhoria na produtividade, clima organizacional agradável, diminuição de rotatividade, assiduidade e pontualidade, dentre outros. No setor público, estes avanços ainda caminham lentamente. Desta maneira, esta pesquisa busca demonstrar a importância e a necessidade na propagação de melhores condiçôes de trabalho. Na busca por demonstrar esta necessidade de melhoria, este estudo será realizado com trabalhadores que exercem os cargos de Apoio Administrativo Educacional (AAE) e os Técnicos Administrativo Educacional (TAE). Estas categorias compóem o que se refere no estado de Mato Grosso no setor da educação como área 21.

Por meio desta pesquisa é possível contextualizar as experiências vividas por esses colaboradores, em seu ambiente de trabalho. Estes relatos permitiram que a equipe gestora da unidade escolar, possa visualizar a realidade vivenciada pelos funcionários. Por meio desta investigação, será possível melhorar as condiçóes de trabalho.

Ao promover melhores condições de trabalho, os funcionários tendem a se motivarem e de se sentirem pertencentes a organização, contribuindo a toda comunidade escolar, desde a gestão até aos pais e responsáveis. Ao despertar este sentimento, eles produziriam melhores resultados ao executar suas atividades, que posteriormente irá agregar valor nos resultados apresentados à sociedade, via unidade de ensino.

A presente pesquisa, busca responder o seguinte problema: Qual a percepçáo dos funcionários do Apoio Administrativo Educacional e Técnico Administrativo Educacional, que fazem parte da Escola Estadual Professora Edith Pereira Barbosa, sobre Qualidade de Vida no Trabalho?

Para alcançar respostas ao problema apresentado, foi aplicado um questionário aos funcionários da Escola Estadual Professora Edith Pereira Barbosa, localizada no município de Rondonópolis-MT, nos quais foram contemplados os setores de limpeza, cozinha, vigilância, auxiliares de turma e secretaria. A escola é composta por 63 funcionários ao total, segundo o gestor. No ano letivo de 2018 a escola atende em média 770 alunos nos períodos matutino e vespertino.

O objetivo que norteia a pesquisa é, identificar qual a percepção dos funcionários sobre QVT, se existe alguma proposta de QVT na Edith Pereira Barbosa e por meio desta proporcionar visibilidade aos educadores que complementam os cargos de apoio e técnico administrativo educacional. 


\section{REFERENCIAL TEÓRICO}

\subsection{ORIGEM DA QUALIDADE DE VIDA NO TRABALHO}

Segundo Lacombe (2009), a Teoria das Relações Humanas surgiu na década de 1930, a qual foi fundamentada em maior parte por Elton Mayo. A partir das contribuiçóes da Teoria das Relaçóes Humanas, os indivíduos passam a ser vistos como sujeitos dotados de necessidades sociais, de se comunicar e interagir com o meio onde está inserido.

Maximiano (2009 p. 213) destaca que "o experimento foi realizado no período de 1927 a 1933 e fez parte de um programa mais amplo, orientado pelo professor Elton Mayo, de Harvard, e que durou até 1947". O autor se refere ao estudo de Hawthorne que, de acordo com Lacombe (2009), este estudo buscou identificar melhorias na produtividade, por meio das variáveis, iluminação, temperatura, ventilação, altura da bancada de produção e estimular os funcionários por meio de remuneração. Conforme apresentado a preocupação com os colaboradores se iniciou, perante a fatores físicos do ambiente de trabalho e remuneração, atualmente um programa de QVT mantem uma visão completa do trabalhador, visualizando todos seus anseios como ser humano.

A preocupação com a saúde do trabalhador, deu-se início na década de 1950, por meio dos estudos de Eric Trist, realizados no Tavistock Institute - Pizzolato. (SOARES, 2018). Neste sentido, a autora descreve o momento em que se iniciou, ainda que pequena, a preocupação com a saúde dos colaboradores. A Teoria das Relaçóes Humanas contribuiu diretamente para a melhoria, do ambiente laboral dos indivíduos, mesmo que timidamente até o presente momento.

A partir da década de 1970, a Qualidade de Vida no Trabalho, passou ter maior visibilidade e aplicabilidade (FERREIRA et al., 2009). Chiavenato (2010), relata que o precursor do termo QVT foi Louis Davis ao desenvolver um desenho sobre cargos e salários.

Afirma Soares (2015), que os fatores relacionados a QVT ganharam importância a partir de 1979, quando as indústrias norte-americanas estadunidenses obtiveram perda competitiva, diante das japonesas, levando a busca de novos estilos gerenciais. A qualidade de vida, dos trabalhadores começou a ganhar espaço, quando as empresas estadunidenses, perceberam que precisavam se destacar estrategicamente, ao analisar que proporcionando melhores condiçōes no ambiente de trabalho, os funcionários desenvolveriam melhores resultados, a QVT atingiu um nível de maior visibilidade dentro dos ambientes organizacionais.

Atualmente, a Qualidade de Vida no Trabalho tem sido trabalhada como fator estratégico nas grandes organizaçōes. Para Amorim (2010, p.37), "hoje, o tema constitui item obrigatório no planejamento estratégico corporativo e é tratado como uma vantagem competitiva no mercado, necessário para atrair e manter bons profissionais." As empresas que se preocupam com sua longevidade precisam se especializar em proporcionar ambientes agradáveis aos seus colaboradores, para que consiga manter os talentos.

Limongi-França (2004), aborda que no Brasil o tema tem despertado o interesse, pelo retorno produtivo, que a QVT proporciona dentro dos ambientes organizacionais. Entretanto, Andrade e Veiga (2012), compreende que, a produtividade é uma consequência, 
e não o objetivo dos projetos de QVT. O aumento da produtividade, e o aumento da qualidade são resultados satisfatórios, para as organizaçóes. Contudo, as empresas devem pensar de forma holística e saber gerir os talentos.

“Toda pessoa é um complexo biopsicossocial, isto é, tem potencialidades biológicas, psicológicas e sociais que respondem simultaneamente as condiçóes de vida" (LIMONGIFRANÇA 1996, p. 146). As organizaçóes necessitam diagnosticar qual a melhor forma de relacionar essas variáveis, biológicas, psicológicas e sociais, dos colaboradores. Por serem, seres dotados de subjetividades cada um deve necessitar de uma atenção diferenciada, o que emprega a necessidade do princípio de equidade no ambiente organizacional.

Porém, Andrade et al. (2018), analisa que no Brasil, a prática da QVT ainda não foi devidamente compreendida pelas organizaçóes e por seus gestores. Apesar de ser um tema bastante abordado, alguns gestores ainda não conseguem compreender a amplitude e a necessidade de se obter um programa de qualidade de vida aos funcionários. Entretanto, esses relatos são vivenciados com maior frequência em empresas menores, as multinacionais contemplam grandes exemplos na questão de proporcionar boas condiçóes de trabalho aos seus funcionários.

A gestão que busca proporcionar QVT no ambiente organizacional, deve se caracterizar como uma gestão dinâmica, pois as pessoas mudam constantemente, dependendo do local em qual estão inseridas (ARAÚJO, 2010). Os indivíduos são seres dotados, por suas subjetividades, princípio, que os tornam únicos. Desta forma, uma gestão que se preocupa em proporcionar um ambiente agradável deve ter uma visão ampla e ao mesmo tempo individual. Cada colaborador tem fatores peculiares que podem ser utilizados como motivador. Então, conforme citado pela autora, é primordial que a gestão seja dinâmica e flexível.

\subsubsection{Qualidade de Vida no Trabalho - QVT}

Ao passar dos anos a qualidade de vida no trabalho, foi se desenvolvendo e se mostrando cada vez mais imprescindível para as organizações. Com sua evolução, foi se diagnosticando os mais variados impactos que podem causar nas organizaçóes. Araújo (2010, p. 31) ressalta que, "com o surgimento da Teoria das Relaçóes Humanas, novos pressupostos passaram a ser considerados no campo organizacional - motivação, liderança, comunicação, organização informal, dinâmica de grupo, etc.” O autor ressalta os diversos campos que a Teoria da Relaçóes Humanas passou a atingir, buscando proporcionar um ambiente laboral mais agradável e proativo. Nos dias atuais as empresas precisam se dedicar a prevenir as novas doenças ocupacionais que tem surgido, as doenças psicológicas.

O exercício laboral compreende a uma parcela grande do tempo das pessoas, o que influencia nas dinâmicas das relaçóes sociais e pessoais (AMORIM, 2010). O trabalho faz parte do cotidiano das pessoas, e atualmente tem se tornado cada vez mais crítico, ao considerar todo o tempo que é desprendido pelo trabalhador para percorrer o caminho de ida e volta do trabalho, complementando com as horas de seu expediente. Com o aumento populacional, o processo de locomoção nas cidades torna cada vez mais demorado e estressante o processo laboral do trabalhador. 
Ferreira et al. (2009) relaciona, que a implantaçâo de programas de QVT, realizados de maneira participativa, o qual afirma uma relação para o bem-estar eficiência e eficácia. O convite para participar de decisóes, desperta um sentimento de importância, nos colaboradores que contribui para que estes se sintam valorizados.

Chiavenato (2010) afirma que a QVT assimila duas vertentes: de um lado, as reivindicaçóes dos funcionários e de outro, o interesse das empresas quanto aos efeitos sobre a produtividade e qualidade. Neste sentido, o autor afirma que para ser competitivo, os fatores de qualidade e produtividade passam obrigatoriamente pela QVT.

Limongi-França e Zaima (2002), no estudo de QVT, é fundamental adotar uma visão biopsicossocial. Que segundo eles se trata, da visão integrada, holística do ser humano. Limongi-França (1996), complementa que, a inserção da QVT depende dessa visualização dos seres humanos como um todo. As empresas precisam adotar o comportamento de visualizar os funcionários, não só como empregados, mais também como pessoas que contemplam toda vida pessoal, fora do ambiente de trabalho.

Um PQVT tem como meta gerar uma organização mais humanizada, na qual os trabalhadores adquirem relativo grau de responsabilidade e de autonomia, tendo "feedback" sobre o seu desempenho, com tarefas adequadas, variedade, enriquecimento pessoal do indivíduo. É importante observar que nem todos os problemas de produtividade das empresas e nem todo tipo de insatisfação do empregado podem ser resolvidos pela Qualidade de Vida no Trabalho. (PAULA, 2014 p. 21).

A autora relata um fator peculiar sobre o programa de qualidade de vida, onde nem todos os problemas são resolvidos por meio da Qualidade de Vida no Trabalho. Sendo assim, o gestor deve saber analisar quais são as causas dos problemas que envolvem os trabalhadores da organização, para saber determinar qual a melhor decisão a ser tomada.

Chiavenato (2010) aborda como conceito fundamental da QVT, o profundo respeito pelas pessoas. Quando há respeito entre as partes envolvidas no ambiente organizacional fica mais fácil a implementação do programa de QVT. A partir do respeito com o próximo, fica nítido a percepção de compreensão da importância e necessidade do trabalho do outro.

Limongi-França (2004, p. 32), "há inquietudes, individuais e coletivas, quanto a pressōes, conciliação da expectativa entre trabalho, família e consumo, sinais de stress, hábitos alimentares e cuidados físicos, estilo de vida, impactos tecnológicos". Com a afirmaçáo da autora, fica destacado que alguns aspectos e dimensóes em que a qualidade de vida interfere na esfera pessoal de cada indivíduo, abordando o quão extenso é a abrangência da qualidade de vida. Ultimamente, a maior parte dos indivíduos mantem diariamente uma alta carga de funçôes e obrigaçóes pessoais e profissionais, o que facilita desencadear o stress.

\subsection{TEORIA DE WALTON (1973)}

Para Ferreira et al. (2009), Walton estabelece que a QVT depende do equilíbrio entre o trabalho e as demais esferas da vida, do papel social da empresa e da importância de se relacionar, a produtividade com a qualidade de vida no trabalho. Soares (2018) relata que o modelo de Walton (1973), é considerado um dos mais completos, devido aos fatores 
abordados. O modelo apresentado por Walton (1973), é composto por oito fatores que compóem a qualidade de vida no trabalho, dos indivíduos.

Quadro 1: Modelo de Walton (1973)

\begin{tabular}{|l|l|}
\hline $\begin{array}{c}\text { Fatores de qualidade de vida no trabalho } \\
\text { (QVT) }\end{array}$ & \multicolumn{1}{c|}{ As dimensóes } \\
\hline 1-Relação ao salário justo e adequado & $\begin{array}{l}\text { Igualdade dos salários, participação na organização, } \\
\text { recompensas, benefícios a alimentação e saúde }\end{array}$ \\
\hline 2- Condiçôes de trabalho & $\begin{array}{l}\text { Horas trabalhadas, uso de tecnologias, condiçóes, } \\
\text { equipamentos individual e coletivo, cansaço }\end{array}$ \\
\hline 3- O uso das capacidades no trabalho & $\begin{array}{l}\text { Oportunidade de decisão, autonomia, cumpri } \\
\text { várias tarefas, avaliação do desempenho. }\end{array}$ \\
\hline 4- Oportunidades no trabalho & $\begin{array}{l}\text { Oportunidade, treinamentos incentivos e } \\
\text { rotatividade }\end{array}$ \\
\hline 5- Integração social no trabalho & $\begin{array}{l}\text { Discriminação religiosa de gênero e social, } \\
\text { comprometimento, valorizaçáo de iniciativas. }\end{array}$ \\
\hline $\begin{array}{l}\text { 6- Constitucionalismo respeito às leis de } \\
\text { trabalho }\end{array}$ & $\begin{array}{l}\text { Direitos, liberdade de expressão, normas regras } \\
\text { respeito individual. }\end{array}$ \\
\hline 7-Espaço que o trabalho ocupa & $\begin{array}{l}\text { Influência do trabalho e da rotina familiar, } \\
\text { possibilidade ao lazer, horas de descanso. }\end{array}$ \\
\hline $\begin{array}{l}\text { 8- Relevância social e a importância do } \\
\text { trabalho }\end{array}$ & $\begin{array}{l}\text { Orgulho no trabalho, imagem que a organizaçáo } \\
\text { representa para a sociedade. integraçáo comunitária }\end{array}$ \\
\hline
\end{tabular}

Fonte: Soares (2018).

Os fatores apresentados por Walton (1973), complementam todo e qualquer ambiente organizacional. No setor público existem algumas particularidades, que podem engessar a tomada de decisão do gestor, relacionado a burocracia que embarca este setor.

No tocante, o fator, salário justo e adequado, se trata de um salário que proporcione ao colaborador, a possibilidade de saudar suas dívidas e que possa proporcionar momentos de lazer. No ambiente público para os que ocupam cargos efetivos são amparados, por um plano de carreira, o qual garante alguns aumentos ao decorrer da mesma.

As condições de trabalho, segundo Walton (1973), relacionam as horas trabalhadas, condiçóes de trabalho, equipamentos e o cansaço. Dentro do ambiente escolar público, relacionado aos funcionários técnicos e do apoio. A carga horária é composta por seis horas diárias, o que compreende a trinta horas semanais. Por se tratar de um ambiente público, geralmente há falta de alguns equipamentos necessários. Esta ausência se dá pela quantia financeira de verba repassada, para as escolas.

O uso das capacidades no trabalho, de acordo com o modelo, apresenta as características como: oportunidades de decisão, autonomia, cumprir várias tarefas, e avaliação de desempenho. Por meio da falta de programas de Qualidade de Vida no 
Trabalho, no setor público, geralmente a maioria desses fatores acabam não tendo o devido reconhecimento e importância.

Oportunidades de trabalho, nas unidades estaduais, os funcionários da área 21, tem uma formação voltada para suas funçóes. Entretanto apesar de existir algum desenvolvimento, geralmente não se relaciona o bem-estar dos colaboradores, somente a execução, desenvolvimento, qualidade e melhoria no serviço prestado. $O$ que torna ineficiente o trabalho realizado, pois a maioria dos estabelecimentos públicos até buscam qualidade no serviço ofertado, porém não trabalha ou busca proporciona melhores condiçóes aos seus colaboradores.

O fator sobre integração social no trabalho, nas unidades, mesmo as mais preocupadas com o bem-estar, existe uma certa diferenciação, entre os funcionários e os professores. A diferenciação já está imposta, desde o momento em que se difere professor de funcionário. Sendo que todos são profissionais da educação, cada um com suas determinadas funçóes.

Sobre o constitucionalismo, a respeito das leis de trabalho, no ambiente escolar público estadual, existem leis que contemplam os direitos e deveres dos servidores públicos. As quais prezam pela moral e os bons costumes.

O espaço ocupado pelo expediente, garante aos funcionários tempo hábil para que possa desfrutar de sua vida particular. São seis horas consecutivas trabalhadas ao dia. O que garante um bom espaço de tempo para que o trabalhador possa se dedicar a sua vida pessoal. Entretanto principalmente por se tratar de funçóes operacionais, os trabalhadores, acabam adquirindo um desgaste físico significativo.

Proporcionar aos funcionários um sentimento de bem-estar, garante que os trabalhadores exerçam com melhor desempenho suas funçóes. Ao se sentir pertencentes as unidades escolares, estes irão internalizar a importância da organização e passar este sentimento adiante, contribuindo para que a sociedade tenha uma visão positiva da unidade escolar.

\subsection{QUALIDADE DE VIDA NO SETOR PÚBLICO}

Andrade et al. (2018), afirma a necessidade da QVT, tanto no setor público, quanto no setor privado, pois compreende as necessidades físicas, psicológicas e as condiçóes de trabalho. $\mathrm{O}$ autor relata a necessidade de se investir em QVT, em todas as organizaçóes, sendo elas privadas ou públicas. Entretanto, Amorim (2010 p. 36) "no setor público, ainda não se evidenciam muitas iniciativas na estruturação e implantação desses programas”.

Apesar de ser primordial em todos os ambientes organizacionais, a Qualidade de Vida no Trabalho ainda não atingiu um status de necessidade na maioria dos estabelecimentos públicos brasileiros. Fator que, complementa o grande índice, de má qualidade, ao serviço prestado.

Amorim relaciona a qualidade do atendimento, as condiçóes vivenciadas de trabalho, dos funcionários.

Dessa forma, o bom nível de atendimento às necessidades dos clientes depende, em grande parte, da satisfação do funcionário, público ou privado, durante a consecução do 
seu exercício funcional. Para melhorar o nível de atendimento ao contribuinte-cliente (AMORIM, 2010 p. 37).

O autor menciona que, de forma significativa o bem-estar, relacionado ao ambiente de trabalho do indivíduo, interfere na maneira em que o mesmo irá atender seus clientes (cidadãos). Situaçóes como stress, cansaço, acúmulo de serviço ocasiona em um desempenho insatisfatório por parte do colaborador. No setor público, pela falta necessária de servidores para a execução das atividades, o acúmulo de atividades é frequentemente presenciado.

\begin{abstract}
A aplicação da QVT na administração pública é capaz de preencher uma lacuna verificada, ao longo dos anos, no nível de tratamento oferecido ao servidor público relativa à valorizaçáo do seu trabalho e preocupaçáo com o seu bem-estar e o de sua família. O gestor público tem maior dificuldade em desenvolver seu processo de gestão e decisão, pois se encontra constantemente preso às amarras legais, como limites de investimentos estabelecidos no orçamento, licitação, estrutura de cargos e carreira dos servidores, dentre outros. (AMORIM, 2010 p. 38).
\end{abstract}

O autor aborda a questão do tratamento oferecido aos servidores públicos que geralmente é precário. Entretanto ele também relata as dificuldades que os gestores passam, relatando a processo burocrático, que compreende o setor público.

Elencado por Ferreira, Alves e Tostes (2009), o novo paradigma organizacional vai se afirmando, não é suficiente mais garantir somente a qualidade do produto ou serviço final, é excepcional que esse resultado seja acompanhado pela Qualidade de Vida no Trabalho. Quando se trata de qualidade do produto final, as organizaçóes que presam por este fator diferencial, precisam garantir condiçóes adequadas aos seus colaboradores e irem se adaptando conforme as mudanças e necessidades de seus funcionários. Buscando manter o nível produtivo destes indivíduos.

\title{
3. CARACTERIZAÇÁO DO AMBIENTE DE PESQUISA
}

A pesquisa foi realizada na Escola Estadual Professora Edith Pereira Barbosa. O Diretor relatou que a chave da escola foi entregue a ele no dia 5 de dezembro de 2015, dando início as suas atividades administrativas no ano letivo de 2016. A unidade de ensino possui $2.408,33 \mathrm{~m}^{2}$ construídos, deste total $1.711,14 \mathrm{~m}^{2}$ são de construção coberta, segundo o gestor. O prédio é composto por dois pisos, inferior e superior, rampa, refeitório, duas escadas e quadra esportiva. Por ter piso branco, a unidade necessita de cuidados especiais de limpeza para que possa estar em perfeitas condiçóes.

A amostra utilizada na coleta de dados foram os profissionais que contemplam os cargos de Apoio Administrativo Educacional e Técnico Administrativo Educacional na unidade. O quadro de funcionários da escola, segundo o gestor, é de 63 profissionais (professores e demais funcionários) sendo 20 que fazem parte da área de apoio e técnico, 43 profissionais são professores, três destes atualmente fazem parte da gestáo da unidade escolar, sendo um diretor e dois coordenadores pedagógicos. O diretor também relata que do total de funcionários da escola, 4 estão em desvio de função, sendo dois do apoio administrativo educacional e dois professores. 
No ano letivo de 2019, a escola atende cerda de 770 alunos, distribuídos nos turnos matutino e vespertino segundo o gestor. Ele também afirma que esse número oscila, de acordo com as matrículas e transferências que são realizadas no decorrer do ano letivo.

\section{PROCEDIMENTOS METODOLÓGICOS-}

Esta pesquisa é de caráter descritivo, que segundo Gil (2008), a pesquisa descritiva é como um objeto fundamental para descrição das peculiaridades de determinado grupo, fenômeno ou relaçóes entre variáveis. A presente pesquisa busca por meio do método qualitativo, identificar a subjetividade das pessoas que serão entrevistadas, perante suas percepçóes referente a Qualidade de Vida no Trabalho. Caracterizando este estudo como pesquisa de campo, que segundo, Vergara (2013, p.43) se caracteriza como sendo uma "pesquisa de campo é investigaçáo empírica realizada no local onde ocorre ou ocorreu um fenômeno ou que dispóe de elementos para explicá-lo".

A pesquisa é composta por dois roteiros de entrevista, um direcionado aos funcionários e outro ao gestor da unidade escolar. Os roteiros coletaram informações sobre o cotidiano, desenvolvimento das funçôes, carga horária, relaçōes interpessoais, proteção individual, participaçáo nos momentos democráticos, dificuldades enfrentadas. Buscando por meio destas dimensões analisar qual é a percepção dos servidores sobre Qualidade de Vida no Trabalho e se na escola Edith Pereira Barbosa existe algum projeto de QVT.

A pesquisa foi direcionada aos servidores que contemplam os cargos de técnico e apoio administrativo educacional da Escola Estadual Professora Edith Pereira Barbosa. Conforme o quadro ilustrativo abaixo:

Quadro 2: Dados da pesquisa

\begin{tabular}{|l|c|}
\hline \multicolumn{2}{|c|}{ Dados numéricos } \\
\hline No total de funcionários & 20 \\
\hline Convidados & 16 \\
\hline Concluiu a entrevista & 11 \\
\hline Não concluiu a entrevista & 1 \\
\hline Não deram retorno & 4 \\
\hline
\end{tabular}

Fonte: A pesquisa, 2019.

Este trabalho busca dar visibilidade aos trabalhadores de apoio educacional, que geralmente são esquecidos no processo de qualidade e bem-estar no ambiente organizacional.

A coleta de dados foi realizada nos meses de junho e julho de 2019. A amostra foi estabelecida de acordo com os cargos que necessitam de maior visibilidade se tratando de proporcionar melhorias no ambiente de trabalho dentro do ambiente escolar. A análise de conteúdo foi o método utilizado para realizar a análise de dados da pesquisa, conforme Gil (2010).

O roteiro aplicado aos funcionários por meio do aplicativo WhatsApp, contempla sete questóes distribuídas entre alguns fatores da Teoria de Walton (1973). Walton selecionou 
as variáveis que mais se faziam presentes no ambiente de trabalho, buscando identificar situaçóes que interfira na qualidade e satisfação do colaborador, questionando também sobre a conciliação mediante a vida profissional e pessoal.

O primeiro fator da Teoria de Walton "relação ao salário justo e adequado", relacionada a essa dimensão foi elaborada uma questão aos funcionários, que os questionava se estavam satisfeitos com o salário que recebiam. Apesar de que, esse fator não poder ser alterado partindo do entendimento do gestor, por se tratar do setor público, o salário já é estabelecido conforme o programa de carreira do estado de Mato Grosso. Entretanto, a insatisfação com esse fator pode causar diminuição na motivação do profissional. Por esse motivo, foi elaborada uma pergunta, questionando sobre a satisfação com o valor recebido.

O fator "condiçóes de trabalho" foi que contemplou o maior número de questóes relacionadas ao mesmo. Foram produzidas três questóes sobre esse fator, esse maior número foi determinado buscando maior entendimento do que os funcionários vivenciam em seus locais de trabalho. Neste fator a pesquisa buscou identificar as dificuldades, as condiçóes de trabalho associadas ao cansaço, e o uso de equipamentos de proteção individuais.

O terceiro fator "o uso das capacidades no trabalho" abarcou uma questão associada a oportunidade de decisão. Para buscar identificar, indagou-se aos servidores se participavam de momentos de democracia dentro do ambiente escolar. Buscando coletar informaçóes se eles participavam ou náo, se eram convidados, se eram respeitados quando opinavam.

O quarto fator "oportunidade no trabalho" e o quinto "interação social no trabalho", não foram elaboradas questôes destinadas aos funcionários. Nestes fatores a questão foi direcionada ao gestor da unidade.

O fator "constitucionalismo" foi contemplado com uma indagação, referente a liberdade de expressão, o respeito dentro da organização estudada. O sétimo fator, "espaço que o trabalho ocupa", foi designada uma questão em que indagava se o servidor conseguia conciliar o trabalho e a família. Nesta questão, o trabalho buscou analisar se os trabalhadores conseguiam ter uma conciliação saudável. O último fator "relevância social e a importância do trabalho" também não formularam questôes direcionadas aos funcionários, somente ao gestor.

Resumidamente as questóes as quais foram feitas aos funcionários buscaram na sua maioria identificar os acontecimentos, condições, respeito, participação que ocorrem ou ocorrem no ambiente organizacional, por isso não contemplou alguns dos fatores apresentadas por Walton (1973). A seguir a figura demonstra as dimensóes que foram questionadas aos profissionais. 
Figura 1: Dimensões analisadas

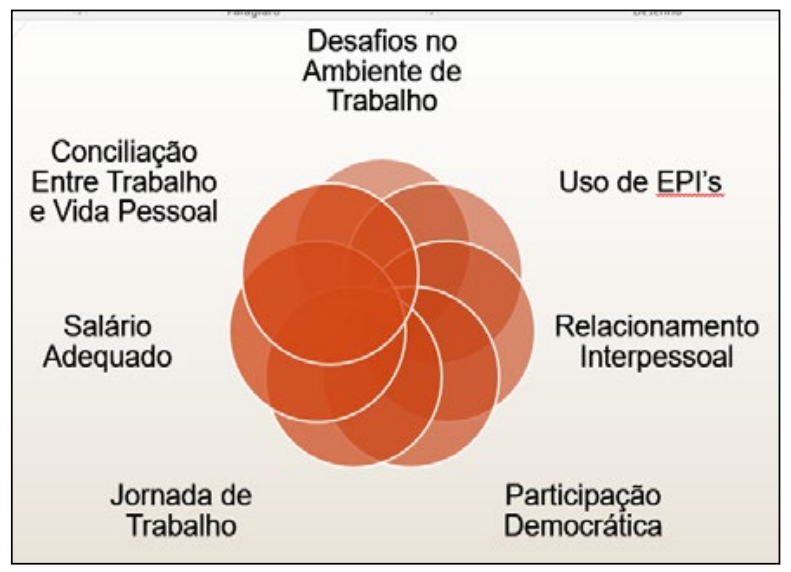

Fonte: A pesquisa, 2019.

Estas dimensóes foram as questionadas aos servidores, estando essas relacionadas aos fatores apresentados pela teoria de Walton, buscando coletar os dados referentes as percepçóes dos colaboradores e relacionando estas dimensóes com a qualidade de vida no trabalho.

$\mathrm{O}$ roteiro destinado ao gestor da escola foi planejado de forma que pudesse permitir uma outra visão sobre os fatores relatados pelos servidores do apoio e técnico. A visão da gestão diante da qualidade de vida dos seus profissionais. Este planejamento foi detalhado, para que permita ao leitor a visão entre os dois lados da moeda. A visão do gestor e a realidade apresentada pelos protagonistas destes cargos.

O roteiro aplicado ao gestor contemplou quase todos os fatores da Teoria de Walton (1973). O único fator que não foi aplicado foi o primeiro, "relação ao salário justo e adequado", por se tratar de uma visão muito subjetiva de cada servidor, esta questão não foi direcionada ao gestor.

O segundo fator "condiçôes de trabalho" o gestor foi questionado sobre dois assuntos, sendo eles, se os seus servidores estavam devidamente equipados para execução de suas funçóes e como era as condiçóes de trabalho dos mesmos. Estes questionamentos buscavam identificar, perante a visão da gestão, como era visto as condiçóes de trabalho, se era um trabalho tranquilo ou cansativo, se tinham condiçóes de desempenhar as funçóes tranquilamente e se a integridade desses funcionários era preservada por meio do uso de equipamentos de proteção individual (EPI) exigidos em alguns cargos.

O fator seguinte aborda "o uso das capacidades no trabalho" sobre esta etapa, o diretor foi questionado sobre sua visão diante dos cargos que compunham a área 21 , o que eles significavam para o andamento diário da organização. O fator "oportunidade no trabalho" e "interação social no trabalho" foram unidos em um único questionamento. Se a gestão escolar valorizava e/ou incentivava as iniciativas por parte dos colaboradores e se os mesmos eram proativos. 
Referente ao "constitucionalismo" foram direcionadas duas indagações ao gestor. A visão do relacionamento interpessoal entre todos os profissionais da unidade escolar e em particular como era o diálogo entre o gestor e os servidores do apoio e técnico administrativo educacional. O sétimo fator "espaço que o trabalho ocupa" contemplou uma questão, a qual questionava o diretor sobre as atividades dos funcionários e suas distribuiçôes diante da carga horária. O último fator que complementa a Teoria de Walton (1973) "relevância social e a importância do trabalho" abarcou uma questáo a qual fazia o gestor apresentar sua percepçáo sobre o olhar dos pais e responsáveis dos alunos diante da qualidade do serviço oferecido por esses funcionários nos setores de limpeza, alimentação, auxiliar, segurança e emissão de documentações.

Quadro 3: Formas de resposta

\begin{tabular}{|l|l|}
\hline Profissionais que responderam por áudio & $\begin{array}{l}\text { Profissionais que responderam por meio da } \\
\text { escrita }\end{array}$ \\
\hline $1,2,3,4,7,8$ e 12 & $5,6,9,10$ e 11 \\
\hline
\end{tabular}

Fonte: A pesquisa, 2019.

De acordo com o método utilizado para realizar a entrevista, os mesmos tinham duas formas de responder as questôes propostas. Eles se dividiram entre os que preferiram agilizar a entrevista, respondendo o questionário por meio da gravaçáo de áudio e outros que se sentiram incomodados em gravar sua própria fala, responderam através da escrita. $\mathrm{O}$ quadro a seguir detalha a forma de resposta de cada servidor.

\section{RESULTADOS}

\subsection{DESAFIOS NO AMBIENTE DE TRABALHO}

O primeiro questionamento direcionado aos entrevistados foi a questão de possíveis desafios enfrentados em seu ambiente de trabalho, o que eles poderiam relatar como dificuldade ou melhorias que pudessem promover condiçôes melhores no seu ambiente de trabalho. Segundo Soares (2015), a qualidade de vida no trabalho tem o papel de amenizar os feitos causados pela exaustão, especialmente quando se utiliza esforço físico. Os cargos de apoio são os que mais sofrem pelo desgaste físico, por exercerem um serviço operacional.

A questão de falta de alguns materiais necessários para a execução da atividade foi questão levantada por alguns colaboradores quando questionados sobre as dificuldades. Outro fator elencado foi a falta de comunicação que ocorre dentro da unidade escolar.

Que as vezes falta, mais é coisa do governo, né! Agente "num" pode nem fica acusando a escola que a gente trabalha. Mais muitas vezes acontece de "num" ter um detergente, agente "tê" que corre atrás [...]. (PROFISSIONAL 2)

No setor público a questáo de verba acaba afetando o processo de aquisiçáo dos materiais necessários para a execução das atividades. Entretanto o servidor apesar de expressar 
sua dificuldade ele compreende que a verba de certa forma afeta na aquisição de materiais. Contudo a falta de utensílios e materiais acabam causando transtorno ao desenvolvimento do trabalho.

Falta de comunicação. A instituição não tem hoje um canal de comunicação entre todos os educadores, e eu vejo isso como um sério problema, já que uma comunicação falha pode trazer serias consequências para uma equipe e até trazer prejuízos para alguns colaboradores [...], não estão abertos a diálogo. (PROFISSIONAL 9)

A questão referente a falta de comunicação foi citada por diversos servidores, esta foi a principal dificuldade elencada. Servidores citaram situaçóes ocasionada por essa falta de comunicação, como: transtornos causados por causa de eventuais ocasiōes que não foram informados com antecedência e também até uma situação em que o funcionário 9 , foi diretamente prejudicado, por não ter sido informado do início da formação oferecida aos profissionais que ocorre dentro do ambiente escolar. Porém quando questionado o gestor, ele obteve uma análise mais positiva, sobre as condições de trabalho de seus funcionários, o gestor afirma que:

Aqui na escola por ser um prédio novo, a estrutura física ajuda muito nessas condições de trabalho [...]. É, eu sempre dou espaço né! A porta da minha sala eu sempre falo que está aberta, quem quiser conversar, dialogar. (GESTOR).

Por mais que o diretor se prontificou ser aberto ao diálogo a uma divergência de opinióes, o servidor 9, esclarece que a gestão náo permite essa acessibilidade, e o servidor 1, afirma que entre a direção e coordenação as vezes agem isoladamente e diversos relatam a falta de comunicação com o setor.

É nítido que a comunicação existente dentro da unidade escolar é falha, servidores são prejudicados ou passam por transtornos, gerados pela falta de comunicaçáo eficiente e ágil entre os setores. Este desafio citado pelos servidores pode e deve ser solucionado pela gestáo, permitindo um melhor desenvolvimento dos processos, e assim garantindo uma melhoria no ambiente de trabalho destes profissionais que compreendem a área 21.

\subsubsection{Uso de Equipamento Individual de Proteçáo}

O uso dos equipamentos de proteção individual é essencial para assegurar a dignidade física do colaborador. De acordo com Paula (2014), é um fator muito importante, na busca por garantir a saúde dos funcionários dentro da organização, por meio dos programas de higiene e segurança no trabalho. Ao se sentir protegido as pessoas desempenham seu papel mais tranquilamente. Conforme os dados apresentados sobre o questionamento aos servidores, se sentiam protegidos. Os que afirmaram se sentirem protegidos, descreveram o porquê de forma tranquila e satisfatória referente a questão, porém os funcionários que afirmaram que não, se mostraram desconfortáveis com essa situação.

Não! "Tá” muito à deseja. "Ééé” faltando nosso equipamento né! Manuseio, muitas coisas "faltano", principalmente a nossa roupa de proteção, nosso sapato. (PROFISSIONAL 2) 
Já foi fornecido as botas e luvas, acho que o que precisa é fornecer máscaras com mais frequência. (PROFISSIONAL 5)

O gestor se mostrou bem proativo nesta questáo de fornecimento de equipamento de proteção, o mesmo afirmou que esses materiais são disponibilizados aos cargos que necessitam e já se pronunciou referente ao uniforme das merendeiras, as mesmas ainda trabalham de forma irregular, não tem o uniforme especializado para exercer a função. Esta irregularidade causa exposição dos profissionais e também aos alunos que consomem a merenda escolar. Diante do questionamento, se era ofertado EPIs aos servidores o gestor relatou:

A escola fornece os equipamentos tanto para o pessoal da limpeza como "pro" pessoal da cozinha. [...] No primeiro ou segundo dia de retorno o pessoal vai vir, "pra" fazer o uniforme das merendeiras e até mesmo porque elas são novas. (GESTOR)

E eu tenho os equipamentos de proteção, então! Eu me sinto sim. (PROFISSIONAL 7)

O servidor 7 expressa sua satisfação perante o uso de equipamentos de proteção individuais que são disponíveis para sua devida proteção.

Gráfico 1: valores respectivos as afirmaçóes dos colaboradores.

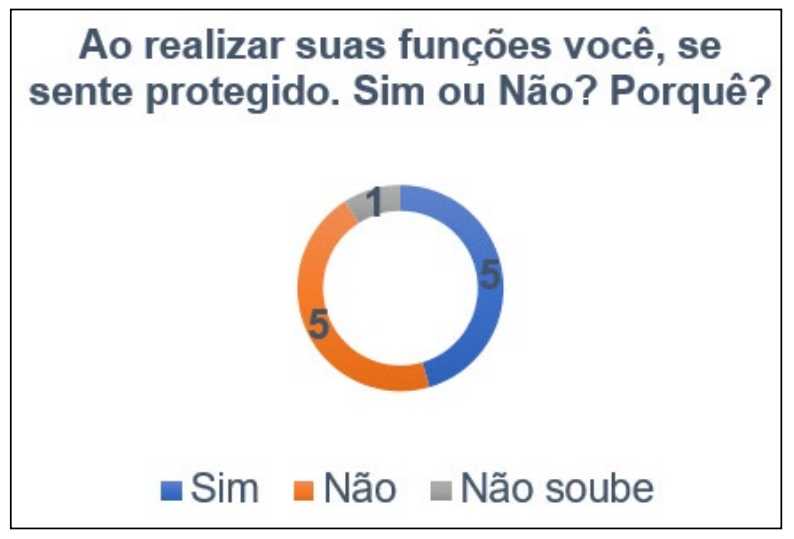

Fonte: A pesquisa, 2019.

De acordo com os dados, metade dos profissionais se sentem protegidos, entretanto outra parte equivalente diz não se sentir devidamente protegido além de ter um profissional que não soube afirmar. Estes números transcendem um fator preocupante pois esses servidores que não se sentem protegidos, podem estar se desgastando, física e psicologicamente diante da situação. A saúde não se trata apenas da ausência de doença, se trata do completo bemestar, sendo ele biológico, psicológico e social (LIMONGI-FRANÇA, 2004).

Limongi-França (2004) descreve a importância da prevenção de doenças associadas aos exercícios das funçóes no local de trabalho, a falta de proteção pode desencadear sérios riscos à saúde do servidor e em especial na área da nutrição escolar, podendo desencadear 
riscos até a própria saúde dos alunos. Para Araújo (2010, p. 29), “o indivíduo que tem a necessidade insatisfeita logo está fora da zona de conforto, está, por assim dizer, incomodado $[\ldots]$...

Segundo os dados apresentados esta divisão partiu de fatores inter-relacionados como: a falta de necessidade de utilização de equipamento individual de proteção para os cargos de técnico e, também de acordo com a percepção de proteção de cada profissional. Alguns trabalhadores, apesar de ter os equipamentos fornecidos, ainda sentia a necessidade de serem fornecidos com maior frequência. Conforme relatado pelo servidor 5 . O setor de nutrição também foi um fator essencial nestes dados, pois os representantes do setor apresentaram não estarem satisfeitos, e que existe a falta de equipamento de proteção, fator afirmado e reconhecido pela própria gestão.

\subsubsection{Relacionamento interpessoal}

"O indivíduo não trabalha somente para a obtenção do salário, o mesmo é um ser integrado e indivisível, trazendo consigo sentimentos, ambiçóes, expectativas, buscando o crescimento dentro daquilo que desenvolve e realiza" (SOARES, 2015 p. 23). Conforme apresentado pelo autor cada indivíduo traz consigo suas experiências e vivências, o que pode causar indiferenças dentro do ambiente organizacional. Quando um ambiente de trabalho é cercado por conflitos, acaba afetando o clima organizacional.

Quando indagados aos profissionais como eles percebiam o relacionamento com os colegas de trabalho, os mesmos se afirmaram que era muito tranquilo, existia harmonia e respeito entre eles. Toda via, quando foi questionado sobre colegas de outros cargos, alguns se manifestaram que percebem uma diferenciação por parte dos mesmos.

Ó em relação a, aos professores, outra reclamação! Né! É só assim, com alguns "profesô" mais não tem "rista", rixa né! Mais tem o tem uma sensaçáo assim que eles se sentem inferiores [...]. É superiores a nós. Falei errado aí. (PROFISSIONAL 2)

A visão da gestão se reafirma com a opinião dos servidores 5, 6, 7, 8, 9 e 10. Contudo os servidores 5, 6 e 8 afirmam ter um bom relacionamento com as demais áreas, mas existe algumas ressalvas que poderiam melhorar. $\mathrm{O}$ diretor descreve.

O relacionamento é tranquilo, o relacionamento é cordial, nós não percebemos assim, rivalidade entre eles, é, ou atrito, pelo menos entre as áreas que agente observa, é tranquilo! (GESTOR)

Por meio dos dados coletados percebe-se que existem funcionários que mantém uma relação saudável entre as demais áreas, entretanto alguns se sentem tratados com diferença pelos demais colegas que ocupam outros cargos dentro da unidade. Contudo nenhum fato grave foi relatado pelos entrevistados. 


\subsubsection{Participaçáo democrática}

Rocha \& Felli (2004) e Lacaz (2000) apud Amorim (2010), relatam que ao participarem da solução de problemas e tomada de decisóes, o nível de percepção sobre QVT aumenta. Os autores estão enfatizando sobre a importância de integrar todos os profissionais na participação de momentos importantes para a organização. Esse posicionamento da gestão faz com que os profissionais se sintam aceitos e importantes para a organização. Conforme a afirmação de Garcia (2017), onde o mesmo diz que é por meio dos indivíduos que os objetivos institucionais são alcançados. Os autores corroboram o fato de que as pessoas são a chave fundamental para o sucesso organizacional.

No ambiente escolar estudado, a questão de participação dos servidores dos cargos de apoio e técnico é um pouco restrito conforme relatado por alguns colaboradores. $\mathrm{O}$ funcionário 8 , afirmou que não foi convidado ou avisado que teria uma reunião referente a adesão à greve, segundo ele quando soube a escola já estava de greve. $\mathrm{O}$ funcionário demonstrou estar incomodado referente esta questão, o mesmo não pode opinar e nem ao menos saber se teve esse momento de debate dentro do ambiente de trabalho. Contribuição de outro colaborador:

Se eu participo "dus", dos movi, movi momentos democráticos dentro da unidade escolar? Não!! Raramente, eu participo. É, na maioria das vezes não, é não. É por falta de convite mesmo, da própria gestáo, da coordenação né! (PROFISSIONAL 4)

Este outro servidor também expressa que na maioria das vezes não é convidado a participar, o que o restringe sobre as informaçóes. Sendo assim alguns funcionários se pronunciaram positivamente referente a essa participação, que participavam e que acredita ser muito importante esses momentos democráticos. No gráfico a seguir fica nítido essa divisão de opinióes.

Gráfico 2: Participação democrática

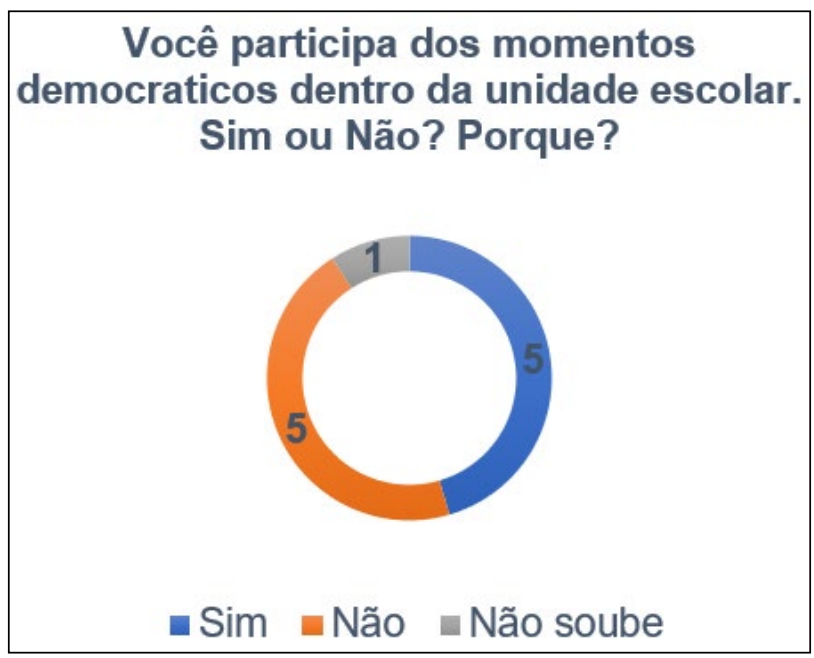

Fonte: A pesquisa, 2019. 
Houve uma divisão em que 5 profissionais afirmam participar e outros 5 dizem que não participam e um servidor que não soube afirmar. Este número realça a necessidade de incorporar os servidores que afirmaram não participar em começar a informá-los, convidálos para esses momentos.

\subsubsection{Jornada de trabalho}

Para Andrade, Laat e Stefano (2018), a qualidade de vida no trabalho tem a finalidade de equilibrar o trabalho, a vida pessoal do profissional, além da produtividade e satisfação com sua atividade. Referente a jornada de trabalho e as funçóes que necessitam ser desempenhadas ao decorrer da mesma, em grande maioria os servidores relatam estarem satisfeitos, que a jornada é tranquila, consegue desempenhar o serviço sem muita dificuldade, esses relatos positivos são afirmados pelos profissionais 1, 2, 3, 6, 8, 9, 10 e 11 . Somente os profissionais 45 , e 7 relataram obter uma jornada cansativa e corrida.

As vezes o horário é pouco porque a gente tem que corre muito! Entendeu? [...] então, o trabalho fica muito concentrado num período, e aí a gente tem que corre muito! (PROFISSIONAL 7)

$\mathrm{Na}$ questão de acúmulo de serviço, dificuldade em desempenhar as atividades, foi específico de dois setores, um em específico que relatou ter um número insuficiente para atender a necessidades do prédio escolar. $\mathrm{O}$ profissional 7 relatou essa dificuldade sofrida por esse setor. No outro setor o profissional 4 descreve que o acúmulo de tarefas se dá pela má distribuição entre o horário e as tarefas. Segundo ele no primeiro momento ele tem tempo sobrando, com tudo no segundo momento ele se desgasta muito para cumprir as tarefas e seu horário.

Agora tanto a parte de limpeza como a cozinha eu acho que o cargo, a quantidade que é ofertada de funcionários é a menos, é menos né! Do que é necessário, principalmente a limpeza! (GESTOR)

O gestor identifica que os setores de limpeza e da cozinha obtêm um número pequeno de funcionários. $\mathrm{O}$ que acaba sobrecarregando os profissionais que fazem parte destas áreas. Toda via o setor da limpeza é o que mais sofre com o cansaço físico. A estrutura da escola é muito grande, sendo dois pisos inferior e superior, além de ter o piso todo branco. $\mathrm{O}$ que exige ainda mais um cuidado especial para manter o aspecto de limpeza.

\subsubsection{Salário adequado}

"Lembram que é importante existir o alinhamento interno e externo da remuneração, pois ela tem impacto direto na vida social do indivíduo, por possibilitar conforto a família, assistência à saúde, educação, lazer e, principalmente, status social". (AMORIM 2010, p. 40). O autor elenca as dimensóes que sofrem influência pela remuneração dos indivíduos, ao julgar a questão salarial o servidor avalia essas questóes, medindo se ele consegue por meio de sua remuneração usufruir das mesmas. 
Sim, em relação minha função ganho razoavelmente bem. Precisaria ganhar mais "pra" realmente obter qualidade de vida melhor [...]. (PROFISSIONAL 10)

Um fator importante é o ingresso de novos profissionais por meio do último concurso público do estado. Ao início da carreira o salário oferecido é o mínimo que os cargos exigem, o aumento ocorrerá conforme ao passar do tempo, com o plano de carreira. O servidor a seguir faz parte da nova remessa de concursados, tendo a princípio o salário inicial. Ele afirma:

Não sou satisfeito! É muito pouco! Não paga as conta! I eu acho que até, porque não valoriza, entendeu? (PROFISSIONAL 7)

Principalmente os cargos de apoio e técnico, iniciam a carreira com um salário que não consegue proporcionar ao profissional conforto e tranquilidade. No início é necessário um controle rígido para conseguir se manter financeiramente. A seguir a visáo geral das opiniôes.

Gráfico 3: Satisfação com o salário

\section{Você está satisfeito com seu salário. Sim ou Não? Porque?}

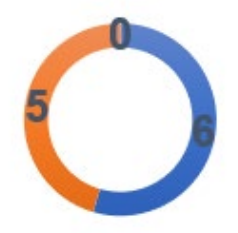

\section{• Sim não Não soube}

Fonte: A pesquisa, 2019.

O gráfico apresenta que existe um número maior de servidores satisfeitos, do que insatisfeitos. Apesar de se tratar de um plano de carreira fixo, estabelecido pelo estado, essa questão foi realizada para que pudessem exprimir a realidade desta dimensão dentro do ambiente escolar estudado.

\subsubsection{Conciliaçáo Entre Trabalho e Vida Pessoal}

$\mathrm{Na}$ visão de Garcia (2017), as más condições exercem impacto sobre o clima e o comportamento organizacional, também sobre a produtividade, impactando até mesmo na vida pessoal do colaborador. Diante das percepçóes dos profissionais analisados, os mesmos em sua maioria se pronunciaram manter uma conciliação tranquila entre o trabalho e a vida pessoal. Em observação, o fato de ser 6 horas diárias, permite que os profissionais tenham um tempo significativo para estar com familiares e administrar seus afazeres pessoais. Esta 
dimensão teve um resultado positivo, a mesma exerce um posicionamento favorável dentro da QVT dos profissionais.

\section{CONSIDERAÇÓES FINAIS}

A qualidade de vida no trabalho está se consolidando cada vez mais no setor privado, com tudo no setor público ainda existe um descaso. Os ambientes públicos organizacionais ainda permanecem engessados, o que compromete as tomadas de decisóes, interferindo no andamento organizacional e comprometendo certamente a qualidade do serviço prestado a sociedade. Dentro da unidade escolar estudada a realidade não é muito diferente. A qualidade dos serviços básicos oferecidos pela unidade de ensino, afeta o bem-estar e satisfação dos estudantes, influenciando no seu ensino aprendizado.

O presente tema, foi designado para permitir maior visibilidade as pessoas que ocupam cargos que prestam serviços técnico e operacional. Geralmente, as pessoas que exercem cargos mais operacionais sofrem por náo ter uma visibilidade e preocupaçáo por parte da gestão. Este foi o propósito deste trabalho, trazer a percepção destes, para que possam transmitir suas necessidades e dificuldades, permitindo que a gestão possa tomar conhecimento da realidade e se posicionar diante do que foi abordado.

Por meio do objetivo de analisar a percepção dos profissionais do apoio e técnico e se havia a existência de algum projeto de QVT, a pesquisa constatou que ainda existe simples fatores administrativos como a comunicação, que não são efetuadas da forma correta, trazendo transtornos aos servidores. Além desta questão outro fator em que foi ressaltado por meio dos relatos foi o distanciamento que existe entre os professores e os profissionais que ocupam os cargos de apoio e técnico administrativo educacional, falta de estrutura na unidade para oferecer um local adequado para as crianças com necessidades especiais, desenvolver atividades também foi relatada pelos profissionais que exercem o papel de acompanhar essas crianças.

Alguns outros fatores também foram elencados como a falta de EPI no setor da nutrição, falta de alguns materiais e acúmulo de serviço no cargo de limpeza, fato que foi afirmado pelo próprio gestor, porém, a unidade não consegue autorização para contratar mais profissionais. Pontos favoráveis foram ressaltados como a satisfaçáo com a jornada de trabalho composta por 30 horas semanais e a facilidade de conciliar a vida profissional com a pessoal. Referente a participação dos momentos democráticos, utilização de equipamentos para garantir a integridade física e a satisfação com o salário recebido, foram variáveis que ficaram divididas entre opiniōes satisfatórias e insatisfatórias.

O desenvolvimento do estudo obteve uma limitação, sobre a forma padrão de se realizar uma entrevista, entretanto esta limitação proporcionou que o trabalho utilizasse o uso da tecnologia para a realizaçáo do mesmo, coletando dados por meio do aplicativo WhatsApp. Em alguns momentos ficou perceptível que alguns dos entrevistados se sentiram intimidados em relatar tudo o que ocorria ou passavam no seu ambiente de trabalho, o que gerou uma limitação diante da apresentação da realidade.

A pesquisa foi desenvolvida e finalizada por 11 colaboradores dos 16 convidados, contendo representantes que contemplam todos os setores que fazem parte da área 21 na 
unidade. $\mathrm{O}$ gestor da unidade escolar também fez parte da pesquisa trazendo suas visões e percepçóes diante das condiçóes de trabalho, relacionamento interpessoal, fornecimento de EPIs, acúmulo de serviço, a qualidade do serviço prestado por esses profissionais. A qualidade de vida dentro do setor público exige a complementação de novos estudos, para que aos poucos vá moldando e inovando dentro deste setor, para que os servidores também usufruam de seu cargo por meio de condiçóes satisfatórias para exercê-lo dando um retorno positivo por meio do serviço prestado a sociedade e disseminar a visão de que serviço público tem uma má qualidade.

\section{REFERÊNCIAS}

AMORIM, Tania Gonçalves Ferreira Nobre. Qualidade de vida no trabalho: Preocupação também para servidores públicos? Revista Eletrônica de Ciência Administrativa (RECADM), Paraná, v. 9, n.1, p. 35-48, 2010.

ANDRADE, Luciana Bortencello Lorenzetti; LAAT, Erivelton Fontana; STEFANO, Silvio Roberto. Qualidade de Vida no Trabalho e Comprometimento com a Carreira de Diretores de Escolas Públicas. Revista Eletrônica de Ciência Administrativa (RECADM), Curitiba, v.17, n.1, p.54-83, 2018.

ANDRADE, Polyana Peres; VEIGA, Heila Magali da Silva. Avaliação dos trabalhadores acerca de um programa de qualidade de vida no trabalho: Validação de escala e análise qualitativa. Psicologia: Ciência e Profissáo, Brasília, v.32, n.2, p.304-319, 2012.

ARAÚJO, Márcia Rios Lamounier. A qualidade de vida no trabalho de professores de escolas públicas. 2010. Dissertação (mestrado em Administração) - Faculdade de Ciências Econômicas, Administrativa e Contábeis, Universidade FUMEC, Belo Horizonte, 2010.

CHIAVEnATO, Idalberto. Gestáo de Pessoas. 3. ed. Rio de Janeiro: Elsevier, 2010.

FERREIRA, Mário Cesar; ALVES, Luciana; TOSTES, Natalia. Gestão de Qualidade de Vida no Trabalho (QVT) no serviço Público Federal: O descaso entre problemas e práticas gerenciais. Psicologia: Teoria e Pesquisa, Brasília, v. 25, n.3, p. 319-327, 2009.

FERREIRA, Rodrigo R. et al. Concepçóes e implantação de um programa de qualidade de vida no trabalho so setor público: $O$ papel estratégico dos gestores. Revista de Administraçáa (RAUSP), São Paulo, v.44, n.2, p.147-157, 2009.

GIL, Antonio Carlos. Como elaborar Projetos de Pesquisa. 4 ed. São Paulo: Atlas, 2008. GIL, Antonio Carlos. Como elaborar projetos de pesquisa. 5 ed. São Paulo: Atlas, 2010. LACOMBE, Francisco José Masset. Teoria geral da administração. 1 ed. São Paulo: Saraiva; 2009. 
LIMONGI-FRANÇA, Ana Cristina. Indicadores empresariais de qualidade de vida no trabalho: esforço empresarial e satisfação dos empregados no ambiente de manufaturas com certificação ISSO 9000. 1996. Tese (Doutor em Administração) -Faculdade de Economia, Administração e Contabilidade, Universidade de São Paulo, São Paulo, 1996.

LIMONGI-FRANÇA, Ana Cristina. Qualidade de vida no trabalho-QVT: conceitos e práticas nas empresas da sociedade pós-industrial. 2 ed. São Paulo: Atlas, 2004.

LIMONGI-FRANÇA, Ana Cristina; ZAIMA, Gustavo. Gestão de qualidade de vida no trabalho- QVT: Com ênfase em pessoas, equipes e liderança. In: BOORG, Madalena; Gustavo. (Org). Manual de gestão de pessoas e equipes: Estratégias e tendências. 7.ed. São Paulo: Gente, 2002. p. 403-421.

MAXIMIANO, Antonio Cesar Amaru. Teoria geral da administração: da revolução urbana à revolução digital. 6 ed. Sáo Paulo: Atlas, 2009.

PAULA, Luara Carvalho Alves. Qualidade de vida no trabalho. 2004. Monografia (Especialista) Faculdade Integrada da AVM, Brasília, 2014.

RICHARDSON, Roberto Jarry. Pesquisa social: métodos e técnicas. 4 ed. São Paulo: Atlas, 2017.

SILVA, Ivanderson Pereira; ROCHA, Fernanda de Burgos. Implicaçóes do uso do whatsapp na educação. Revista EDaPECI. São Cristóvão, v. 17, n. 2, p. 161-174, 2017.

SOARES, Ilane Dantas. A qualidade de vida no trabalho dos professores das escolas estaduais do município de Lagoa Nova/RN. 2015. Monografia (Graduação em Administração) - Universidade Federal do Rio Grande do Norte, Natal, 2015.

SOARES, Luciene de Jesus e Silva. Qualidade de Vida no Trabalho dos professores do Ensino Médio da rede pública e privada: o caso comparativo em cinco escolas de Rondonópolis Mato Grosso. 2018. Monografia (Graduação em Administração) Universidade Federal de Mato Grosso, Rondonópolis, 2018.

VERGARA, Sylvia Constant. Projetos e relatórios de pesquisa em administração. 14 ed. São Paulo: Atlas, 2013. 